\title{
Intraventricular haemorrhage and posthaemorrhagic ventricular dilatation: moving beyond CSF diversion
}

\author{
${\text { Aswin } \text { Chari }^{1,2} \text { (D) Conor Mallucci }}^{3} \cdot$ Andrew Whitelaw $^{4} \cdot$ Kristian Aquilina $^{1,2}$
}

Received: 20 April 2021 / Accepted: 4 May 2021 / Published online: 15 May 2021

(C) The Author(s) 2021

\begin{abstract}
Advances in medical care have led to more premature babies surviving the neonatal period. In these babies, germinal matrix haemorrhage (GMH), intraventricular haemorrhage (IVH) and posthaemorrhagic ventricular dilatation (PHVD) are the most important determinants of long-term cognitive and developmental outcomes. In this review, we discuss current neurosurgical management of IVH and PHVD, including the importance of early diagnosis of PHVD, thresholds for intervention, options for early management through the use of temporising measures and subsequent definitive CSF diversion. We also discuss treatment options for the evolving paradigm to manage intraventricular blood and its breakdown products. We review the evidence for techniques such as drainage, irrigation, fibrinolytic therapy (DRIFT) and neuroendoscopic lavage in the context of optimising cognitive, neurodevelopmental and quality of life outcomes in these premature infants.
\end{abstract}

Keywords Germinal matrix haemorrhage $\cdot$ Intraventricular haemorrhage $\cdot$ Posthaemorrhagic ventricular dilatation $\cdot$ Temporising device $\cdot$ Premature $\cdot$ Neuroendoscopic lavage

\section{Introduction}

About 1 in 10 babies is born preterm, and this number appears to be increasing in regions with reliable data [1]. The incidence of intraventricular haemorrhage (IVH) in preterm babies remains high at around $25-30 \%$ and increases with lower gestational ages and birth weights; the incidence in very premature infants weighing $500-750 \mathrm{~g}$ is $40 \%[2,3]$. IVH occurs secondary to germinal matrix haemorrhage $(\mathrm{GMH})$; the germinal matrix is still abundant up to 32 weeks' gestation and contains fragile and unsupported arterioles and capillaries,

Kristian Aquilina

Kristian.aquilina@gosh.nhs.uk

1 Department of Neurosurgery, Great Ormond Street Hospital, London, UK

2 Developmental Neurosciences, Great Ormond Street Institute of Child Health, University College London, London, UK

3 Department of Neurosurgery, Alder Hey Children's Hospital, Liverpool, UK

4 Neonatal Neuroscience, Translational Health Sciences, University of Bristol, Bristol, UK with poor capacity to autoregulate. This pressure-passive circulation is susceptible to haemorrhage when rapid changes in blood pressure or respiratory distress occur [4].

Improvements in medical care have increased survival beyond the neonatal period. In these survivors, the presence of IVH is one of the most important determinants of cognitive outcomes and the need for special education [5, 6]. In a cohort of 75 children with large intraparenchymal echodensities, $68 \%$ demonstrated cognitive function below $80 \%$ of normal [7]. Similar outcomes are identified in larger meta-analyses [8]. Some changes in neonatal care have resulted in effective prevention of IVH. Historically, the incidence of GMH-IVH was highest with the introduction of positive pressure ventilation to neonatal intensive care in the 1960s and subsequently fell as the haemodynamic impact of ventilation was better understood and the use of antenatal steroids became standard care in the 1990s $[9,10]$. However, postnatal administration of phenobarbital to control blood pressure fluctuations is associated with no change in IVH or developmental outcomes, and meta-analysis has found little evidence for delayed cord clamping in reducing IVH incidence [11, 12].

Prompt management of IVH and its sequelae is therefore crucial to optimising long-term developmental outcomes in this cohort of premature infants. Brain injury results from the initial GMH itself, the toxic effects of the blood and its 
breakdown products, particularly free iron in the ventricles, an inflammatory response with influx of activated macrophages and specific injury to oligodendrocyte precursor cells, and the effect of raised intracranial pressure on the developing white matter at a time of rapid brain development $[13,14]$. In this review, we outline the current evidence base for management of IVH and its sequelae. In particular, we focus on two aspects - the management of posthaemorrhagic ventricular dilatation (PHVD) and the evolving paradigm of managing the intraventricular blood and its breakdown products in the acute phase.

\section{Initial diagnosis}

Currently, most cases of IVH in premature infants are identified on cranial ultrasound (CrUS), performed soon after birth, routinely or after a period of systemic instability. Neonatal units have established protocols for serial CrUS surveillance following pre-term birth, with closer surveillance at younger gestational ages. The highest risk for bleeding is within the first $48 \mathrm{~h}$ of life and most IVH is diagnosed by day 7; surveillance can then be performed less frequently.

The CrUS is important for establishing two parameters:

- The grade of IVH: this is assessed by the Volpe Grade (Fig. 1a). In general terminology, this is commonly referred to as the synonymous Papile grade, which was initially derived from CT scan findings.

- The degree of PHVD: this is measured by the Ventricular Index (VI, Fig. 1b). The VI is measured from the falx to the lateral wall of the body of the lateral ventricle, measured in the coronal (or axial) plane at the level of the foramen of Monro. Levene produced reference ranges for the VI according to gestational age (weeks 26 to 42). PHVD is a dynamic process and requires serial monitoring. A VI above the $97^{\text {th }}$ centile for the given gestational age is considered high, although specific treatment thresholds are discussed below. Other CrUS measurements such as the anterior horn width (AHW) and thalamo-occipital distance (TOD) are also helpful in guiding management.

Due to the compliance of the neonatal skull and brain, the large extracerebral spaces in preterm infants and the high fluid content of the neonatal brain, VI changes on CrUS precede the clinical signs of ventriculomegaly and raised intracranial pressure (ICP). Tense fontanelle, splayed sutures and rapidly growing head circumference were associated with directly measured mean CSF pressure $9.1 \mathrm{~mm} \mathrm{Hg}$ ranging up to $34 \mathrm{~mm} \mathrm{Hg}$ (upper limit of normal neonatal CSF pressure $6 \mathrm{~mm} \mathrm{Hg}$ ) [15]. If left untreated, further signs of progressive
ICP rise develop such as bradycardia, desaturation, sun setting and engorged scalp veins.

\section{Management of PHVD}

Traditionally, the management of premature infants with IVH has focussed on the treatment of the ensuing PHVD, which affects about $50 \%$ of those with grade 3 or grade 4 IVH. The rationale is that, at least in part, the ventricular dilatation is due to a combination of communicating and obstructive hydrocephalus, and this hydrocephalus is detrimental to the developing brain, resulting in cognitive dysfunction, cerebral palsy and epilepsy. In animal models, the cause of PHVD is multifactorial and involves disruption of normal CSF production, flow and absorption. The accumulation of methaemoglobin from the intraventricular haemoglobin induces the expression of proinflammatory cytokines in a preterm rabbit pup model [16]. Release of transforming growth factor beta from inflammatory cells recruited to the ventricular system and from platelets within the blood clot activates fibroblasts leading to the deposit of fibrin on ependymal surfaces, interfering with the flow and absorption of CSF [17]. In a rat model, the inflammatory response associated with IVH was associated with a significant increase in the secretion of CSF at the choroid plexus epithelium [18].

Definitive treatment of PHVD, in the form of a ventriculoperitoneal (VP) shunt, is associated with high rates of morbidity and failure due to a combination of anaesthetic risk, immunological immaturity, risk of abdominal pathology including necrotising enterocolitis, risk of skin and wound breakdown, valve blockage by blood clot and technical factors associated with operating on such a small neonate. Therefore, the current treatment paradigms involve the use of temporising measures during the neonatal period, with definitive management at or around term-equivalent age. There is currently no role for medical management. A trial of acetazolamide and frusemide in the International PHVD Drug Trial was terminated early as the treatment group had worse outcomes both in terms of shunt placement and death (RR 1.4, $\mathrm{p}=0.03$ ) as well as neurological disability and death (RR 1.4 , $\mathrm{p}=0.01$ ).

A number of landmark studies have explored the current thresholds for intervention in PHVD. Meta-analysis of trials from the 1980s and 1990s has confirmed that lumbar punctures and ventricular taps do not reduce permanent shunt dependence or neurological disability [19]. Equally, waiting until the PHVD becomes clinically significant may be too late [20]. A retrospective comparative study between Dutch and Canadian cohorts found lower rates of cognitive $(\mathrm{p}=0.002)$ and motor $(\mathrm{p}=0.03)$ disability in a cohort whose treatment was initiated when the VI exceeded the $97^{\text {th }}$ centile compared to a cohort whose treatment was initiated in the presence of 
a.

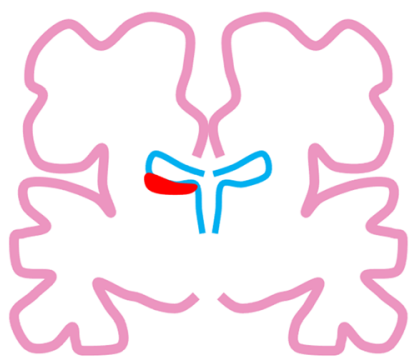

Grade 1: Isolated germinal matrix hemorrhage

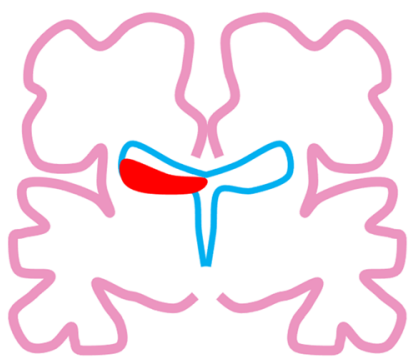

Grade 3: Extension into dilated ventricles

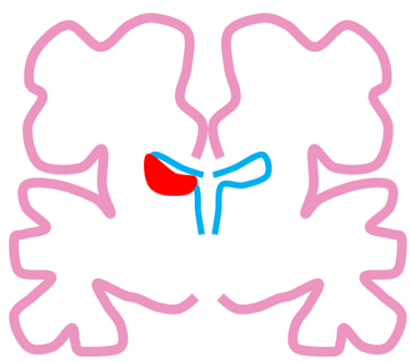

Grade 2: Extension into normal sized ventricles, usually $<50 \%$ of ventricular volume

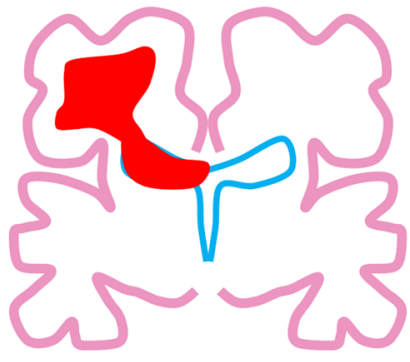

Grade 4: Periventricular hemorrhagic infarction b.

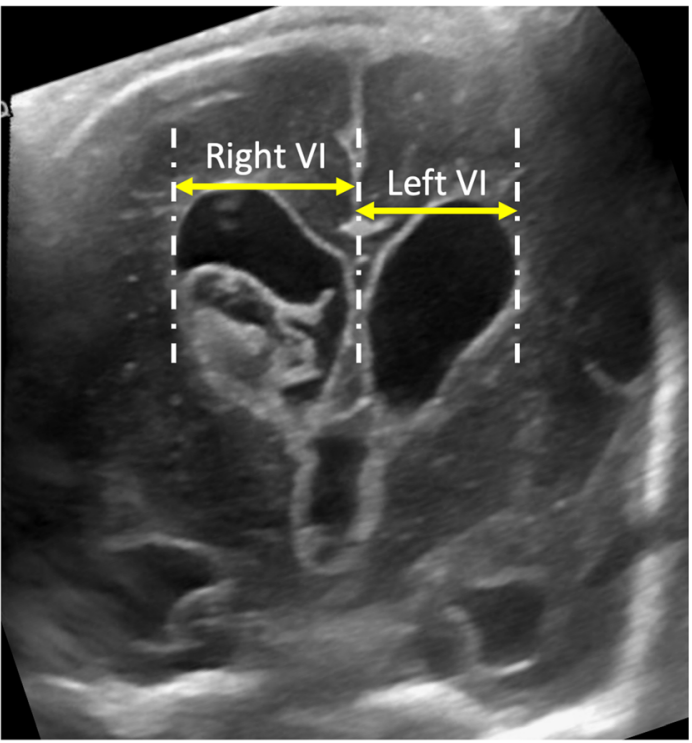

Fig. 1 a CrUS representations of the different IVH grades. b Example measurement of the VI on CrUS

clinical signs of raised ICP [21]. This has recently been evaluated in a randomised controlled trial. The ELVIS (Early versus Late Ventricular Intervention Study) trial has shown that, despite not affecting the composite primary outcome of VP shunt or death, early intervention (VI exceeding the $97^{\text {th }}$ centile or AHW $>6 \mathrm{~mm}$ ) is associated with less disability than late intervention (VI exceeding the $97^{\text {th }}$ centile $+4 \mathrm{~mm}$ or AHW $>10 \mathrm{~mm}$ ); the composite rate of death or disability at 24 months' corrected age was $51 \%$ in the late intervention group and $35 \%$ in the early intervention group (adjusted OR $0.24, \mathrm{p}=0.03)[22,23]$.

\section{Temporising measures}

Once the need for intervention is established, a number of temporising measures may be instituted (Fig. 2). These include lumbar punctures, direct trans-fontanelle ventricular puncture, external ventricular drainage (EVD), ventricular access device (VAD) insertion or ventriculosubgaleal shunt (VSGS) insertion. Lumbar punctures often stop being effective after a number of attempts; ventricular puncture is associated with risks of parenchymal injury, and infection and EVDs require ongoing neurosurgical and neonatal intensive care management, making them unmanageable in many settings.

There is little consensus or standardisation of temporising procedure to perform with significant variation between surgeons and units. This is exemplified in a recent UK survey, which demonstrated a wide variation in practice where respondents noted a preference for VAD (33\%), ventricular puncture (25\%), VSGS (17\%) or repeated lumbar puncture (17\%) [24].

Meta-analyses suggest that VAD and VSGS are equivalent in terms of the risks, rates of subsequent need for permanent VP shunt and subsequent shunt revision rates, although earlier treatment is associated with lower rates of VP shunting and neurological disability [25-27]. Following institution of the temporising measures, ongoing monitoring with regular CrUS, head circumference measurement and clinical assessment are important to ensure ongoing control of the PHVD.

\section{Permanent CSF diversion}

At or around term-equivalent age or when the infant reaches a weight of $1.8-2 \mathrm{~kg}$, there then needs to be a subsequent assessment of whether permanent CSF diversion in the form of a VP shunt is necessary. Individual and institutional practice may vary but this is largely based on the ongoing need for the temporising measures (e.g. VAD taps or VSGS drainage) to control ventricular dimensions [28]. Further information is obtained from clinical assessment, CSF sampling (to ensure protein levels are $<1.5 \mathrm{~g} / \mathrm{L}$ and culture negative) and axial magnetic resonance imaging (MRI) (Fig. 3). In addition to the clinical utility, MRI at term-equivalent age, including assessment of the Kidokoro score and ventricular volumes, has been shown to be useful in predicting subsequent neurodevelopmental outcomes $[29,30]$. In large series, VP shunt conversion rates in the literature vary widely from 63 to $95 \%$ [31-35]. Occasionally in this population, in the context of necrotising enterocolitis, 


\begin{tabular}{l} 
Lumbar Puncture \\
Trans-Fontanelle \\
Ventricular Puncture \\
\hline External Ventricular \\
Drainage (EVD) \\
\hline drainage?
\end{tabular}

Fig. 2 The different temporising measures with accompanying advantages and disadvantages. This image illustrates the relative advantages of the VSG in comparison to other measures, having fully

ventricular-atrial shunts may be required when the peritoneum is unable to cope with CSF absorption.

There is little evidence with respect to the optimal valve type to use in this population. Some advocate using low pressure fixed pressure valves to mitigate for the CSF being proteinaceous with the hope of reducing mechanical obstruction. Others advocate programmable valves as the requirement for internalised hardware with low infection risk with pseudo-continuous drainage that can be managed remotely outside the neuroscience centre

drainage changes over time; adjusting the pressure is purported to mitigate against potential early (overdrainage) and late (slit ventricles) complications [36]. In terms of catheter choice, the recent BASICS study demonstrated a significant 3-fold reduction in shunt infection using antibiotic impregnated catheters compared to standard or silver impregnated catheters [37].

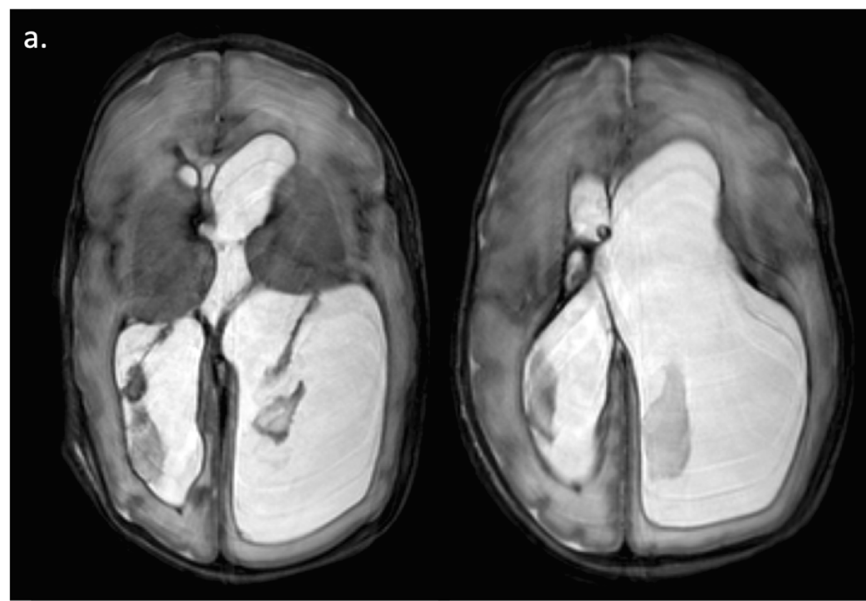

Fig. 3 Example MRIs at term-equivalent age with VSG in situ. a Ongoing ventricular dilatation. A subsequent VP shunt was inserted to manage this. b Well-controlled ventricles. In combination with clinical

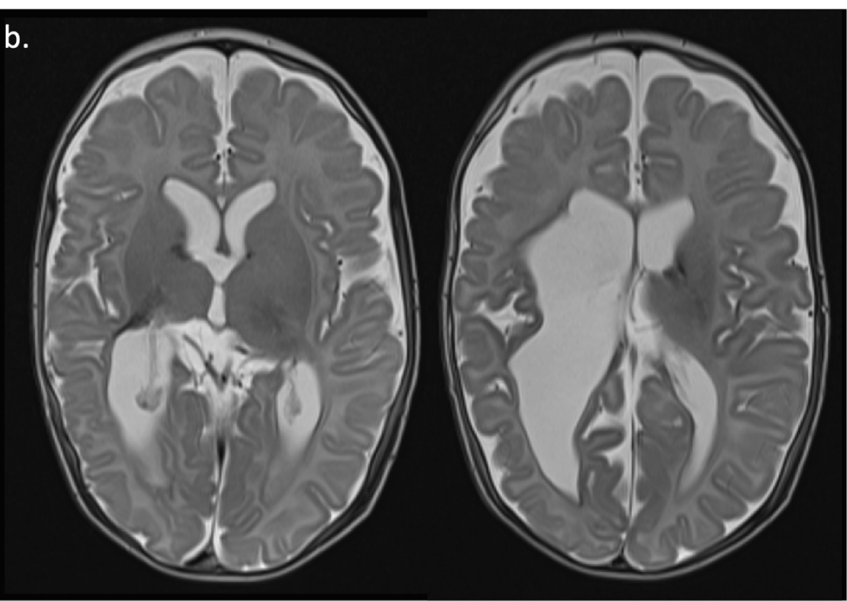

assessment, VP shunt insertion was deemed not necessary in this infant and, a few weeks later, the VSG was removed 
Beyond the initial haemorrhagic period, the hydrocephalus associated with PHH is traditionally considered as mainly a communicating hydrocephalus and therefore not amenable to treatment with endoscopic third ventriculostomy with choroid plexus coagulation. This has however been used with limited success in some published series [38,39]. Authors argue that, despite the limited success (37-40\%), the demonstrated safety makes it a worthwhile consideration as it may obviate the need for permanent VP shunt, especially if imaging reveals some favourable characteristics, including aqueduct stenosis or a non-scarred and patent prepontine cistern on preoperative MRI.

\section{Management of the blood and breakdown products}

Infants with well-controlled PHVD, even with intervention at an early stage, still suffer from neurological disability [23]. In addition, infants with grades I and II IVH also develop neurological disability [40]. This can be due to the effect of the initial haemorrhage itself (that is only modifiable by preventative strategies to reduce the incidence of GMH) or due to the toxic effects of the blood and blood breakdown products on the developing brain.

The best evidence of our ability to modify this factor comes from the drainage, irrigation and fibrinolytic therapy (DRIFT) studies. DRIFT involved the insertion of two EVDs for drainage, intraventricular administration of recombinant tissue plasminogen activator and irrigation with artificial CSF at a point when the VI was at least on the $97^{\text {th }}$ centile plus $4 \mathrm{~mm}$. The procedure was carried out in the neonatal ICU, and irrigation was continued for at least $72 \mathrm{~h}$ to allow clearance of blood and its breakdown products from the CSF. The trial was discontinued prematurely due to the small chance that the short-term primary outcome (requirement for a VP shunt or death) at 6 months will be significantly different between the DRIFT and standard treatment groups. The study however did demonstrate a significant reduction in the proportion of children with severe cognitive disability or death at 2 years in the DRIFT arm, from 71 to 54\% (adjusted OR 0.25) [41, 42]. This benefit was maintained at 10-year follow-up [43]. The mean cognitive quotient score was 69.3 in the DRIFT group and 53.7 in the standard treatment group; this improved cognition at 10 years was equivalent to a 2 -year developmental delay [43]. These results represented the most marked improvement in cognition and survival with any intervention after IVH and PHVD. A study that used network meta-analysis methodology to evaluate the outcome of ten different trials for PHVD also demonstrated that DRIFT is the most efficacious and the most likely treatment to improve outcomes [44]. Despite this, however, the DRIFT technique has not been widely adopted and has not changed standard practice due to the resource- intensive nature of the treatment and the potential risks of secondary haemorrhage.

An alternative to DRIFT that is less resource intensive is neuroendoscopic lavage (Fig. 4), which involves the use of an endoscope to gently irrigate the ventricular CSF, clearing the ventricles of any large clots and restoring CSF flow via a septostomy and ensuring patency of the foramina of Monro. To date, there is no class I evidence of its efficacy but retrospective evaluations have had encouraging results with the procedure showing safety, reductions in VP shunt insertion and revision rates and favourable neurodevelopmental outcome [45-49]. There have been no prospective comparative trials. Specifically, the neurodevelopmental outcomes have not been systematically assessed; the only study to do so only assessed cognitive outcomes in $61 \%$ of infants alive at 2 years, with $30 \%$ having cognitive profiles within the normal range [45].

\section{Future directions}

There are multiple avenues to improve the long-term outcomes of premature infants with IVH.

A first important consideration is the selection and measurement of endpoints in clinical studies. Whilst early trials focussed on VP shunt dependence and revision rates, results from the DRIFT and ELVIS studies have shown that developmental outcomes can improve despite unchanged VP shunt dependency. Patient involvement initiatives have confirmed that cognitive and developmental outcomes are the most important outcomes for patients, and this should be the focus of future trials $[50,51]$. This may be further strengthened and homogenised by the development of core sets of outcome measures that will facilitate cross-study comparisons and the progress of international registries such as TROPHY $[52,53]$. Whilst the current standard in these studies has been developmental assessment at 2 years' corrected gestational age, further work may identify earlier biomarkers of eventual neurodevelopmental outcome that will facilitate more rapid investigation [54].

The prevention of GMH, IVH and PHVD is crucial to improving neurological outcomes. Although detailed discussion of this may be beyond the scope of this review, risk factors including fetal, maternal, delivery-related and haemodynamic have been reviewed elsewhere and it remains to be seen whether these can effectively be modified to alter incidence [9].

In terms of managing the PHVD, recent progress has advocated for early intervention via temporising measures, and it seems that VAD and VSGS are largely equivalent in efficacy and long-term outcomes. The impact of adjustable versus fixed pressure valves for definitive VP shunts is an area that requires further study, as is the role of non-shunt procedures such as endoscopic third ventriculostomy with choroid plexus coagulation, especially in resource-limited settings. 


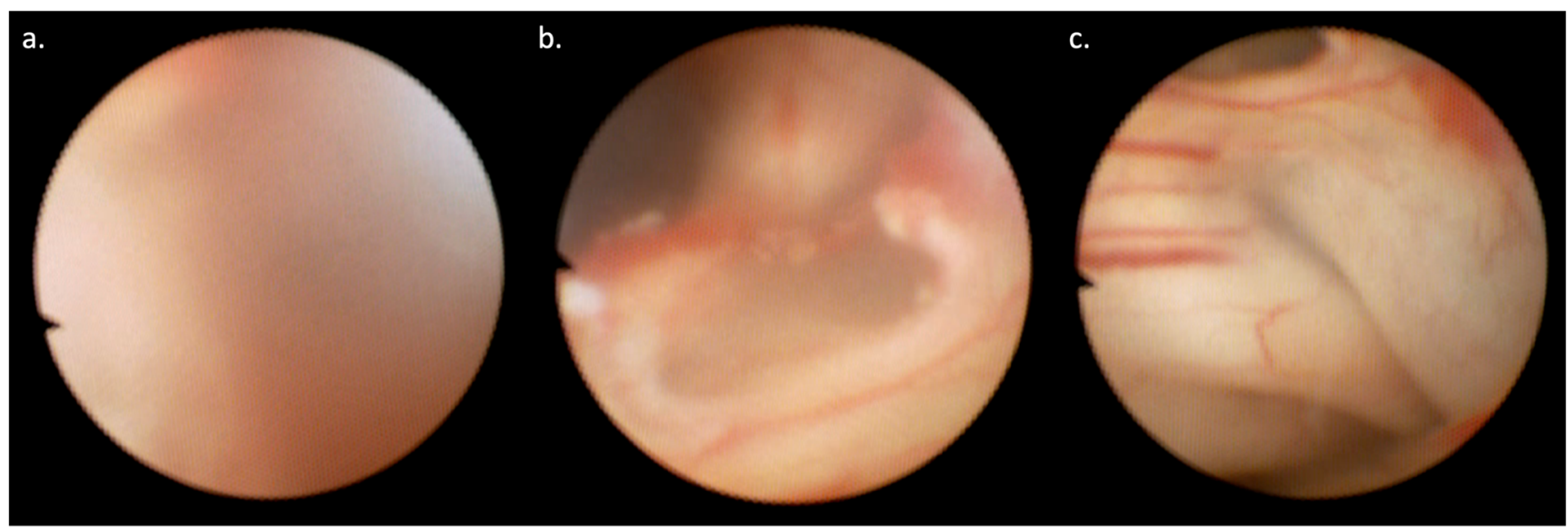

Fig. 4 Typical views during the a beginning, $\mathbf{b}$ middle and $\mathbf{c}$ end of a neuroendoscopic lavage procedure. Whilst the CSF is bloodstained and views are very difficult to obtain at the beginning of the procedure, as the procedure progresses, the CSF becomes clearer, affording better views of

Further research into the direct management of intraventricular blood and its breakdown products is required. Despite the incidence and developmental impact of IVH and PHVD, only about 700 infants have been enrolled into intervention trials, and fewer than 500 have had long-term developmental measures reported [44]. The role of surgical and medical therapies in removing the blood and reducing its toxicity on the developing brain requires robust evaluation and may hold the potential to further improve developmental outcomes in premature neonates with IVH.

\section{Conclusion}

The management of GMH-IVH and PHVD in premature infants has evolved considerably over the last few decades. The management of PHVD at an early stage through temporising devices followed by subsequent permanent CSF diversion has led to reductions in morbidity and complications. The paradigm of clearing the blood and its breakdown products is in its relative infancy, with neuroendoscopic lavage showing promise of being a safe and effective procedure. In conjunction with prevention of IVH, this holds the key to progress in optimising cognitive, neurodevelopmental and quality of life outcomes in these premature infants.

Author contribution All authors contributed to the drafting and editing of the manuscript. All authors have reviewed and approve the final version of the manuscript for submission.

Funding AC is supported by a Great Ormond Street Hospital (GOSH) Children's Charity Surgeon Scientist Fellowship. This work has been supported by the GOSH-National Institute of Health Research Biomedical Research Centre. the ventricular walls and anatomy. Towards the end, the foramina of Monro are visualised and a septostomy is attempted to ensure CSF flow (not shown)

Code availability Not applicable

\section{Declarations}

Conflict of interest None.

Open Access This article is licensed under a Creative Commons Attribution 4.0 International License, which permits use, sharing, adaptation, distribution and reproduction in any medium or format, as long as you give appropriate credit to the original author(s) and the source, provide a link to the Creative Commons licence, and indicate if changes were made. The images or other third party material in this article are included in the article's Creative Commons licence, unless indicated otherwise in a credit line to the material. If material is not included in the article's Creative Commons licence and your intended use is not permitted by statutory regulation or exceeds the permitted use, you will need to obtain permission directly from the copyright holder. To view a copy of this licence, visit http://creativecommons.org/licenses/by/4.0/.

\section{References}

1. Blencowe H, Cousens S, Oestergaard MZ, Chou D, Moller AB, Narwal R, Adler A, Vera Garcia C, Rohde S, Say L, Lawn JE (2012) National, regional, and worldwide estimates of preterm birth rates in the year 2010 with time trends since 1990 for selected countries: a systematic analysis and implications. Lancet 379: 2162-2172. https://doi.org/10.1016/S0140-6736(12)60820-4

2. Gale C, Statnikov Y, Jawad S, Uthaya SN, Modi N, Brain Injuries expert working group (2018) Neonatal brain injuries in England: population-based incidence derived from routinely recorded clinical data held in the National Neonatal Research Database. Arch Dis Child Fetal Neonatal Ed 103:F301-F306. https://doi.org/10.1136/ archdischild-2017-313707

3. Christian EA, Jin DL, Attenello F, Wen T, Cen S, Mack WJ, Krieger MD, McComb JG (2016) Trends in hospitalization of preterm infants with intraventricular hemorrhage and hydrocephalus in the United States, 2000-2010. J Neurosurg Pediatr 17:260-269. https://doi.org/10.3171/2015.7.PEDS15140 
4. Ballabh P (2010) Intraventricular hemorrhage in premature infants: mechanism of disease. Pediatr Res 67:1-8. https://doi.org/10.1203/ PDR.0b013e3181c1b176

5. van de Bor M, den Ouden L (2004) School performance in adolescents with and without periventricular-intraventricular hemorrhage in the neonatal period. Semin Perinatol 28:295-303. https://doi.org/ 10.1053/j.semperi.2004.08.007

6. Wilson-Costello D, Friedman H, Minich N, Siner B, Taylor G, Schluchter M, Hack M (2007) Improved neurodevelopmental outcomes for extremely low birth weight infants in 2000-2002. Pediatrics 119:37-45. https://doi.org/10.1542/peds.2006-1416

7. Guzzetta F, Mercuri E, Spanò M (1995) Mechanisms and evolution of the brain damage in neonatal post-hemorrhagic hydrocephalus. Childs Nerv Syst 11:293-296. https://doi.org/10.1007/ BF00301763

8. Mukerji A, Shah V, Shah PS (2015) Periventricular/intraventricular hemorrhage and neurodevelopmental outcomes: a meta-analysis. Pediatrics 136:1132-1143. https://doi.org/10.1542/peds.2015-0944

9. Gilard V, Tebani A, Bekri S, Marret S (2020) Intraventricular hemorrhage in very preterm infants: a comprehensive review. J Clin Med 9:2447. https://doi.org/10.3390/jcm9082447

10. Hefti MM, Trachtenberg FL, Haynes RL, Hassett C, Volpe JJ, Kinney HC (2016) A century of germinal matrix intraventricular hemorrhage in autopsied premature infants: a historical account. Pediatr Dev Pathol 19:108-114. https://doi.org/10.2350/15-061663-OA.1

11. Smit E, Odd D, Whitelaw A (2013) Postnatal phenobarbital for the prevention of intraventricular haemorrhage in preterm infants. Cochrane Database Syst Rev:CD001691. https://doi.org/10.1002/ 14651858.CD001691.pub3

12. Rabe H, Gyte GM, Díaz-Rossello JL, Duley L (2019) Effect of timing of umbilical cord clamping and other strategies to influence placental transfusion at preterm birth on maternal and infant outcomes. Cochrane Database Syst Rev 9:CD003248. https://doi.org/ 10.1002/14651858.CD003248.pub4

13. Ballabh P, de Vries LS (2021) White matter injury in infants with intraventricular haemorrhage: mechanisms and therapies. Nat Rev Neurol 17:199-214. https://doi.org/10.1038/s41582-020-00447-8

14. Volpe JJ (2009) Brain injury in premature infants: a complex amalgam of destructive and developmental disturbances. Lancet Neurol 8:110-124. https://doi.org/10.1016/S1474-4422(08)70294-1

15. Kaiser AM, Whitelaw AG (1985) Cerebrospinal fluid pressure during post haemorrhagic ventricular dilatation in newborn infants. Arch Dis Child 60:920-924

16. Gram M, Sveinsdottir S, Ruscher K, Hansson SR, Cinthio M, Åkerström B, Ley D (2013) Hemoglobin induces inflammation after preterm intraventricular hemorrhage by methemoglobin formation. J Neuroinflammation 10:867. https://doi.org/10.1186/ 1742-2094-10-100

17. Whitelaw A, Cherian S, Thoresen M, Pople I (2004) Posthaemorrhagic ventricular dilatation: new mechanisms and new treatment. Acta Paediatr Suppl 93:11-14. https://doi.org/10. 1111/j.1651-2227.2004.tb03041.x

18. Karimy JK, Zhang J, Kurland DB, Theriault BC, Duran D, Stokum JA, Furey CG, Zhou X, Mansuri MS, Montejo J, Vera A, DiLuna ML, Delpire E, Alper SL, Gunel M, Gerzanich V, Medzhitov R, Simard JM, Kahle KT (2017) Inflammation-dependent cerebrospinal fluid hypersecretion by the choroid plexus epithelium in posthemorrhagic hydrocephalus. Nat Med 23:997-1003. https://doi. org/10.1038/nm.4361

19. Whitelaw A, Lee-Kelland R (2017) Repeated lumbar or ventricular punctures in newborns with intraventricular haemorrhage. Cochrane Database Syst Rev 4:CD000216. https://doi.org/10. 1002/14651858.CD000216.pub2

20. de Vries LS, Liem KD, van Dijk K, Smit BJ, Sie L, Rademaker KJ, Gavilanes AW, Dutch Working Group of Neonatal Neurology
(2002) Early versus late treatment of posthaemorrhagic ventricular dilatation: results of a retrospective study from five neonatal intensive care units in The Netherlands. Acta Paediatr 91:212-217. https://doi.org/10.1080/080352502317285234

21. Leijser LM, Miller SP, van Wezel-Meijler G, Brouwer AJ, Traubici J, van Haastert IC, Whyte HE, Groenendaal F, Kulkarni AV, Han KS, Woerdeman PA, Church PT, Kelly EN, van Straaten HLM, Ly LG, de Vries LS (2018) Posthemorrhagic ventricular dilatation in preterm infants: when best to intervene? Neurology 90:e698. https://doi.org/10.1212/WNL.0000000000004984

22. de Vries LS, Groenendaal F, Liem KD, Heep A, Brouwer AJ, van 't Verlaat E, Benavente-Fernández I, van Straaten $\mathrm{H}$, van WezelMeijler G, Smit BJ, Govaert P, Woerdeman PA, Whitelaw A, ELVIS study group (2019) Treatment thresholds for intervention in posthaemorrhagic ventricular dilation: a randomised controlled trial. Arch Dis Child Fetal Neonatal Ed 104:F70-F75. https://doi. org/10.1136/archdischild-2017-314206

23. Cizmeci MN, Groenendaal F, Liem KD, van Haastert IC, Benavente-Fernández I, van Straaten HLM, Steggerda S, Smit BJ, Whitelaw A, Woerdeman P, Heep A, de Vries LS, Han KS, ter Horst HJ, Dijkman KP, Ley D, Fellman V, de Haan TR, Brouwer AJ, Benders MJNL, Dudink J, Verlaat E', Govaert P, Swarte RMC, Rijken M, van Wezel-Meijler G, Quijano TA, Barcik U, Mathur AM, Graca AM (2020) Randomized controlled early versus late ventricular intervention study in posthemorrhagic ventricular dilatation: outcome at 2 years. J Pediatr 226:28-35.e3. https://doi.org/10.1016/j.jpeds.2020.08.014

24. Kumar N, Al-Faiadh W, Tailor J et al (2017) Neonatal posthaemorrhagic hydrocephalus in the UK: a survey of current practice. Br J Neurosurg 31:307-311. https://doi.org/10.1080/ 02688697.2016.1226260

25. Badhiwala JH, Hong CJ, Nassiri F, Hong BY, Riva-Cambrin J, Kulkarni AV (2015) Treatment of posthemorrhagic ventricular dilation in preterm infants: a systematic review and meta-analysis of outcomes and complications. J Neurosurg Pediatr 16:545-555. https://doi.org/10.3171/2015.3.PEDS14630

26. Fountain DM, Chari A, Allen D, James G (2016) Comparison of the use of ventricular access devices and ventriculosubgaleal shunts in posthaemorrhagic hydrocephalus: systematic review and metaanalysis. Childs Nerv Syst 32:259-267. https://doi.org/10.1007/ s00381-015-2951-8

27. Lai GY, Chu-Kwan W, Westcott AB, Kulkarni AV, Drake JM, Lam SK (2021) Timing of temporizing neurosurgical treatment in relation to shunting and neurodevelopmental outcomes in posthemorrhagic ventricular dilatation of prematurity: a meta-analysis. J Pediatr. https://doi.org/10.1016/j.jpeds.2021.01.030

28. Mazzola CA, Choudhri AF, Auguste KI, Limbrick DD, Rogido M, Mitchell L, Flannery AM (2014) Pediatric hydrocephalus: systematic literature review and evidence-based guidelines. Part 2: management of posthemorrhagic hydrocephalus in premature infants. $\mathrm{J}$ Neurosurg Pediatr 14(Suppl 1):8-23. https://doi.org/10.3171/2014. 7.PEDS14322

29. Cizmeci MN, Khalili N, Claessens NHP, Groenendaal F, Liem KD, Heep A, Benavente-Fernández I, van Straaten HLM, van WezelMeijler G, Steggerda SJ, Dudink J, Išgum I, Whitelaw A, Benders MJNL, de Vries LS, Han K, Woerdeman P, ter Horst HJ, Dijkman KP, Ley D, Fellman V, de Haan TR, Brouwer AJ, van 't Verlaat E, Govaert P, Smit BJ, Agut Quijano T, Barcik U, Mathur A, Graca AM (2019) Assessment of brain injury and brain volumes after posthemorrhagic ventricular dilatation: a nested substudy of the randomized controlled ELVIS trial. J Pediatr 208:191-197.e2. https://doi.org/10.1016/j.jpeds.2018.12.062

30. Tully HM, Wenger TL, Kukull WA, Doherty D, Dobyns WB (2016) Anatomical configurations associated with posthemorrhagic hydrocephalus among premature infants with intraventricular 
hemorrhage. Neurosurg Focus 41:E5. https://doi.org/10.3171/ 2016.8.FOCUS16241

31. Limbrick DD, Mathur A, Johnston JM, Munro R, Sagar J, Inder T, Park TS, Leonard JL, Smyth MD (2010) Neurosurgical treatment of progressive posthemorrhagic ventricular dilation in preterm infants: a 10-year single-institution study. J Neurosurg Pediatr 6:224-230. https://doi.org/10.3171/2010.5.PEDS1010

32. Bock HC, Feldmann J, Ludwig HC (2018) Early surgical management and long-term surgical outcome for intraventricular hemorrhage-related posthemorrhagic hydrocephalus in shunttreated premature infants. J Neurosurg Pediatr 22:61-67. https:// doi.org/10.3171/2018.1.PEDS17537

33. Wellons JC, Shannon CN, Holubkov R, Riva-Cambrin J, Kulkarni AV, Limbrick DD, Whitehead W, Browd S, Rozzelle C, Simon TD, Tamber MS, Oakes WJ, Drake J, Luerssen TG, Kestle J (2017) Shunting outcomes in posthemorrhagic hydrocephalus: results of a Hydrocephalus Clinical Research Network prospective cohort study. J Neurosurg Pediatr 20:19-29. https://doi.org/10. 3171/2017.1.PEDS16496

34. Riva-Cambrin J, Shannon CN, Holubkov R, Whitehead WE, Kulkarni AV, Drake J, Simon TD, Browd SR, Kestle JR, Wellons JC 3rd, Hydrocephalus Clinical Research Network (2012) Center effect and other factors influencing temporization and shunting of cerebrospinal fluid in preterm infants with intraventricular hemorrhage. J Neurosurg Pediatr 9:473-481. https:// doi.org/10.3171/2012.1.PEDS11292

35. Christian EA, Melamed EF, Peck E, Krieger MD, McComb JG (2016) Surgical management of hydrocephalus secondary to intraventricular hemorrhage in the preterm infant. J Neurosurg Pediatr 17:278-284. https://doi.org/10.3171/2015.6.PEDS15132

36. Gebert A-F, Schulz M, Schwarz K, Thomale U-W (2016) Longterm survival rates of gravity-assisted, adjustable differential pressure valves in infants with hydrocephalus. J Neurosurg Pediatr 17: 544-551. https://doi.org/10.3171/2015.10.PEDS15328

37. Mallucci CL, Jenkinson MD, Conroy EJ, Hartley JC, Brown M, Dalton J, Kearns T, Moitt T, Griffiths MJ, Culeddu G, Solomon T, Hughes D, Gamble C, Pettorini B, Parks C, Sinha A, van Tonder L, Foster MT, McMahon C, Buxton N, Chavredakis E, Brodbelt AR, Lawson DDA, Eldridge PR, Farah JO, Zakaria R, Geraint S, Solanki G, Rodrigues D, Edwards R, Williams A, Garnett M, Kolias A, Hutchinson PJA, Caldwell K, Tarantino S, Leach P, Zaben M, Zilani G, Shastin D, Merola J, Hussain R, Vemaraju R, Selezneva L, Radford G, Lloyd N, Crimmins D, Caird J, Sayar MN, O'Mahoney N, Thompson D, Aquilina K, James G, Strachan R, Mukerji N, Zebain B, Thakur B, Dickson H, Nsirim E, Adebayo A, Goodden J, Deniz K, Clarke J, Kambafwile M, Anderson I, Chave-Cox R, Sheik A, Mathew R, Richards O, Mukherjee S, Chumas P, Tyagi A, Sikakumar G, Toma A, D'Antona L, Watkins L, Thorne L, Craven C, Bassen V, Holliman D, Coulter I, Macarthur D, Cartmill M, Howarth S, Smith S, Javed S, Kamaly I, Ramirez R, King A, Nadig A, Thorne J, Ushewokunze S, Sinha S, Zaki H, McMullan J, Bulters D, Waters R, Zilidis G, Roach J, Sadek A, Holton P, Zolnourian A, Chakraborty A, Kandasamy J, Hughes M, Brennan PM (2019) Antibiotic or silver versus standard ventriculoperitoneal shunts (BASICS): a multicentre, singleblinded, randomised trial and economic evaluation. Lancet 394: 1530-1539. https://doi.org/10.1016/S0140-6736(19)31603-4

38. Warf BC, Campbell JW, Riddle E (2011) Initial experience with combined endoscopic third ventriculostomy and choroid plexus cauterization for post-hemorrhagic hydrocephalus of prematurity: the importance of prepontine cistern status and the predictive value of FIESTA MRI imaging. Childs Nerv Syst 27:1063-1071. https:// doi.org/10.1007/s00381-011-1475-0

39. Chamiraju P, Bhatia S, Sandberg DI, Ragheb J (2014) Endoscopic third ventriculostomy and choroid plexus cauterization in posthemorrhagic hydrocephalus of prematurity. J Neurosurg Pediatr 13: 433-439. https://doi.org/10.3171/2013.12.PEDS13219

40. Patra K, Wilson-Costello D, Taylor HG, Mercuri-Minich N, Hack M (2006) Grades I-II intraventricular hemorrhage in extremely low birth weight infants: effects on neurodevelopment. J Pediatr 149: 169-173. https://doi.org/10.1016/j.jpeds.2006.04.002

41. Whitelaw A, Jary S, Kmita G, Wroblewska J, Musialik-Swietlinska E, Mandera M, Hunt L, Carter M, Pople I (2010) Randomized trial of drainage, irrigation and fibrinolytic therapy for premature infants with posthemorrhagic ventricular dilatation: developmental outcome at 2 years. Pediatrics 125:e852-e858. https://doi.org/10. 1542/peds.2009-1960

42. Whitelaw A, Evans D, Carter M, Thoresen M, Wroblewska J, Mandera M, Swietlinski J, Simpson J, Hajivassiliou C, Hunt LP, Pople I (2007) Randomized clinical trial of prevention of hydrocephalus after intraventricular hemorrhage in preterm infants: brainwashing versus tapping fluid. Pediatrics 119:e1071-e1078. https:// doi.org/10.1542/peds.2006-2841

43. Luyt K, Jary S, Lea C, Young GJ, Odd D, Miller H, Kmita G, Williams C, Blair PS, Fernández AM, Hollingworth W, Morgan M, Smith-Collins A, Thai NJ, Walker-Cox S, Aquilina K, Pople I, Whitelaw A (2019) Ten-year follow-up of a randomised trial of drainage, irrigation and fibrinolytic therapy (DRIFT) in infants with post-haemorrhagic ventricular dilatation. Health Technol Assess 23:1-116. https://doi.org/10.3310/hta23040

44. Mahoney L, Luyt K, Harding D, Odd D (2020) Treatment for posthemorrhagic ventricular dilatation: a multiple-treatment meta-analysis. Front Pediatr 8. https://doi.org/10.3389/fped.2020.00238

45. Behrens P, Tietze A, Walch E, Bittigau P, Bührer C, Schulz M, Aigner A, Thomale UW (2020) Neurodevelopmental outcome at 2 years after neuroendoscopic lavage in neonates with posthemorrhagic hydrocephalus. J Neurosurg Pediatr 26:1-9. https://doi.org/ 10.3171/2020.5.PEDS20211

46. d'Arcangues C, Schulz M, Bührer C, Thome U, Krause M, Thomale UW (2018) Extended Experience with neuroendoscopic lavage for posthemorrhagic hydrocephalus in neonates. World Neurosurg 116:e217-e224. https://doi.org/10.1016/j.wneu.2018. 04.169

47. Schulz M, Bührer C, Pohl-Schickinger A, Haberl H, Thomale UW (2014) Neuroendoscopic lavage for the treatment of intraventricular hemorrhage and hydrocephalus in neonates. J Neurosurg Pediatr 13:626-635. https://doi.org/10.3171/2014.2.PEDS13397

48. Tirado-Caballero J, Rivero-Garvia M, Arteaga-Romero F, HerreriaFranco J, Lozano-Gonzalez Á, Marquez-Rivas J (2020) Neuroendoscopic lavage for the management of posthemorrhagic hydrocephalus in preterm infants: safety, effectivity, and lessons learned. J Neurosurg Pediatr 26:1-10. https://doi.org/10.3171/ 2020.2.PEDS2037

49. Etus V, Kahilogullari G, Karabagli H, Unlu A (2018) Early endoscopic ventricular irrigation for the treatment of neonatal posthemorrhagic hydrocephalus: a feasible treatment option or not? A multicenter study. Turk Neurosurg 28:137-141. https://doi.org/10. 5137/1019-5149.JTN.18677-16.0

50. Koschnitzky JE, Wright JM, White M et al (2017) Incorporating the patient voice in hydrocephalus research. 22. https://www.pcori.org/ sites/default/files/T2T-Whitepaper.pdf

51. Tamber MS, Naftel RP (2020) Patient and parental assessment of factors influencing the choice of treatment in pediatric 
hydrocephalus. J Neurosurg Pediatr 26:490-494. https://doi.org/10. 3171/2020.5.PEDS2095

52. Williamson PR, Altman DG, Bagley H, Barnes KL, Blazeby JM, Brookes ST, Clarke M, Gargon E, Gorst S, Harman N, Kirkham JJ, McNair A, Prinsen CAC, Schmitt J, Terwee CB, Young B (2017) The COMET Handbook: version 1.0. Trials 18:280. https://doi.org/ 10.1186/s13063-017-1978-4

53. Thomale U-W, Cinalli G, Kulkarni AV, al-Hakim S, Roth J, Schaumann A, Bührer C, Cavalheiro S, Sgouros S, Constantini S, Bock HC (2019) TROPHY registry study design: a prospective, international multicenter study for the surgical treatment of posthemorrhagic hydrocephalus in neonates. Childs Nerv Syst 35: 613-619. https://doi.org/10.1007/s00381-019-04077-4

54. Dorner RA, Allen MC, Robinson S, Soares BP, Perin J, Ramos E, Gerner G, Burton VJ (2019) Early neurodevelopmental outcome in preterm posthemorrhagic ventricular dilatation and hydrocephalus: Neonatal ICU Network Neurobehavioral Scale and imaging predict 3-6-month motor quotients and Capute Scales. J Neurosurg Pediatr 25:1-11. https://doi.org/10.3171/2019.9.PEDS19438

Publisher's note Springer Nature remains neutral with regard to jurisdictional claims in published maps and institutional affiliations. 